\title{
Wir nehmen die Praxis mit
}

_ Physiotherapeuten sind sich einig, wenn es um die Akademisierung geht: Ja, endlich. Allerdings erlebe ich zunehmend Diskussionen um die Sorge, die Praxis könnte im Studium zu kurz kommen. Befürchtungen sind ein bekanntes Phänomen in Veränderungsprozessen. Mit der Zunahme grundständiger Studiengänge scheinen diese Befürchtungen zu wachsen.

- Vertrauen wir doch einfach den Studiengangsleitern und den Dozenten an den Hochschulen. Sie werden Lösungen finden. Der Schluss, Studium gleich schlechter Praktiker, wäre fatal, denn der Auftrag eines Bachelorstudienganges ist es, reflektierende Praktiker auszubilden und keine Wissenschaftler. Dafür sind die Masterstudiengänge zuständig.

_ Könnte ich mir unabhängig von allen Rahmenbedingungen etwas wünschen, wäre es die 100-prozentige Einführung des grundständigen Studiums der Physiotherapie. Traditionell ausgebildete Therapeuten sollen natürlich übergangsweise weiterhin die Möglichkeit haben, ein Studium nach ihrer Ausbildung zu absolvieren.

_ Der einzige Grund, auf Dauer an Berufsfachschulen festzuhalten, ist Bildungschancen ein Leben lang zu gewähren. Ich verstehe, dass es Menschen gibt, die sich langsam entwickeln und für die es möglich sein muss, ein Studium auf ihre schulische Ausbildung draufzusetzen. Es ist aber kein Grund, langfristig an der schulischen Ausbildung festzuhalten, damit die Praxis nicht verloren geht! Wenn wir nach einem Bachelorstudium nicht behandeln können, brauchen wir es nicht. Die Forschung delegieren wir an die, die zum Master weiterstudieren und dann eventuell promovieren. Deren Ergebnisse stärken den Praktikern den Rücken.

_ Apropos Rücken stärken: Drücken wir der deutschen Mannschaft bei der Fußballweltmeisterschaft der Frauen die Daumen und bereiten ihnen ein Sommermärchen, das dem für die Herren der Schöpfung in nichts nachsteht.

Herzlichst, Ihre

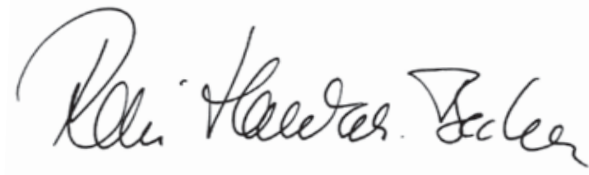

